\title{
Optical and Electron Microscopy Characterization of Alloyed Nanocomposites $\mathrm{CdS}_{\mathrm{X}} \mathrm{Se}_{1-\mathrm{x}}$
}

\author{
A.Khalid ${ }^{a}$, K. Easawi ${ }^{a}$, M. G. El-Shaarawy ${ }^{b}$, S. Negm ${ }^{a}$, and H.Talaat \\ ${ }^{a}$ Department of Mathematical and Physical Engineering , Faculty of \\ Engineering (Shoubra), Banha University, Cairo, Egypt \\ ${ }^{b}$ Physics Department, Faculty of Science, Banha University, Banha, \\ Cairo, Egypt \\ ${ }^{c}$ Physics Department, Faculty of Science, Ain Shams University, \\ Abbassia, Cairo, Egypt.
}

Semiconductor alloy nanocrystals $C d S_{x} S_{e_{1-x}}$ of approximately the same size were fabricated by the chemical solution deposition technique. The observed exciton peaks in the UV-Visible spectra show an increased blue shift with the increase in molar ratio $(x=0 \rightarrow 1)$. The Effective Mass Approximation (EMA) was applied to determine the size of the nanocrystals using Vegard's law applied to the bulk parameters. The calculated sizes of alloy nanocrystals are in a good agreement with the directly measured values obtained using high-resolution transmission electron-microscopy (HRTEM). The band gaps vary slightly for the alloyed nanocrystals having the same size but different molar ratio $x$. The Stock's shifts determined from the Photoluminence (PL) spectra show no a particular behavior due to the similarity of selenium and sulphur component of the nanocrystals.

\section{Introduction}

Semiconductor alloy nanocrystals $\mathrm{CdS}_{\mathrm{x}} \mathrm{Se}_{1-\mathrm{x}}$ are increasingly important in many areas of tunable nanoscale engineering, because of the possible continuous variations of their physical and optical properties through gradual change of the composition variable $x$ [1]. $\mathrm{CdS}_{\mathrm{x}} \mathrm{Se}_{1-\mathrm{x}}$ alloy nanocrystals, spanning the compositional range from pure $\operatorname{CdS}(x=1)$ to pure $\mathrm{CdSe}(x=0)$ [2], would have band gaps energies ranging over $150 \mathrm{~nm}$. The matching of the absorption active layers in the photovoltaic cell to large span of the solar spectrum has the effect of increasing the efficiency of the solar photovoltaic cells. Different selenium and sulphur precursor's ratios were used to tune the internal structures of the alloy nanoparticles (NPs) [3]. This makes $\mathrm{CdS}_{\mathrm{x}} \mathrm{Se}_{1-\mathrm{x}}$ a potentially favorable material for photovoltaic applications [4], where nanocrystals of the same size but with varying energy band gap can be advantageous. The UV-Visible spectroscopy was carried out to determine exciton peak of alloy NPs. Vegard's law [5] that is normally applied in the bulk 
calculations to obtain the relevant parameters like the band gaps of alloys, was applied in this work to get the coresponding parameters for the nanostructures. Therefore, we were able to apply the Effective Mass Approximation (EMA) to determine the size of nanocrystals[6]. The calculated nanocomposition sizes were compared with the direct measurements using high-resolution transmission electron-microscopy (HRTEM), and found in agreement within experimental error. The Photoluminescence (PL) spectra were also carried out with UV -Visible spectra to determine Stock's shift for the different composition.

\section{Experimental}

\subsection{Preparation of $\mathrm{CdSe}$ and $\mathrm{CdS}$ quantum dots of increasing sizes:}

(CdSe and CdS) quantum dots and alloy of CdSSe of different ratios between selenium and sulphur colloidal nanocrystals were prepared by the method of Talapin et al. [7]. The typical method to prepare CdSe is as follows: $0.3 \mathrm{~g}$ of $\mathrm{CdO}$ is added to $3.0 \mathrm{~g}$ of stearic acid, and heated up to $170^{\circ} \mathrm{C}$ till the red color of $\mathrm{CdO}$ disappears completely and $\mathrm{CdO}$ is transformed to $\mathrm{Cd}$ sterate. $2.0 \mathrm{~g}$ of trioctylphosphine oxide (TOPO) (to facilitate the preparation of highly monodisperse nanocrystals (size distribution $\leq 5 \%$ ), according to a procedure reported in reference [8]). $1.0 \mathrm{~g}$ hexadecyl amine of (HDA) are added to the reaction mixture and heated at $200{ }^{\circ} \mathrm{C}$. Selenium solution was prepared by mixing $0.3 \mathrm{~g}$ of selenium in $3.0 \mathrm{~mL}$ trioctyl phosphine (TOP). The selenium solution was then injected into the cadmium solution at a temperature $200^{\circ} \mathrm{C}$. Six samples of CdSe were taken at different time intervals $(60 \mathrm{sec}$. to 6 minutes), labeled from (a) to (f). CdS QD was prepared by the same method; where sulphur solution was prepared by mixing $0.3 \mathrm{~g}$ of sulphur in $3.0 \mathrm{~mL}$ TOP. The sulfur solution was then injected into the cadmium solution at a temperature $200^{\circ} \mathrm{C}$. Five samples of CdS were taken at different time intervals (60 sec. to 5 minutes), labeled from (a) to (e).

\subsection{Preparation of alloy $\mathrm{CdS}_{\mathrm{x}} \mathrm{Se}_{1-\mathrm{x}}$ nanocrystals of approximately the same size:}

A series of $\mathrm{CdS}_{\mathrm{x}} \mathrm{Se}_{1-\mathrm{x}}$ samples $(x=0.33,0.5,0.67,0.75)$ were prepared under the same experimental conditions by varying the amount of the second precursor. For the preparation of $\mathrm{CdS}_{0.33} \mathrm{Se}_{0.67}$ sample, cadmium solution was prepared by $0.3 \mathrm{~g}$ of $\mathrm{CdO}$ added to $3.0 \mathrm{~g}$ of stearic acid, and heated up to $170^{\circ} \mathrm{C}$ till the red color of $\mathrm{CdO}$ disappears to ensure that the reaction between $\mathrm{CdO}$ and stearic acid is complete and $\mathrm{CdO}$ completely transform to $\mathrm{Cd}$ sterate. $2.0 \mathrm{~g}$ of (TOPO) and $1.0 \mathrm{~g}$ of (HDA) are added to the reaction mixture and heated at $200^{\circ} \mathrm{C}$. Sulphur solution was prepared by mixing $0.1 \mathrm{~g}$ of sulphur in $1.0 \mathrm{~mL}$ (TOP). Selenium solution was also prepared by dissolving $0.2 \mathrm{~g}$ of selenium in $1.0 \mathrm{~mL}$ (TOP). Appropriate amounts of sulphur and selenium solutions were 
mixed together to give the above ratios. The mixture was then injected into the cadmium solution at a temperature $200^{\circ} \mathrm{C}$. Small volumes of sample were taken at different time interval of (one minute to 8 minutes) after the point of injection and quenched in $5 \mathrm{ml}$ of cold anhydrous toluene $25^{\circ} \mathrm{C}$ to terminate the growth of the particle immediately. The resulting alloyed nanocrystals in toluene solution were precipitated out by using ethanol and isolated by centrifugation and decantation. An extensive purification was done prior to characterization.

UV-Vis absorption spectra were recorded using a double-beamUV-Vis spectrophotmeter (Jasco 670). The size distribution and crystalline structure were determined by high-resolution transmission electron-microscopy (HRTEM) (JEOL JEM-2100 operated at 200KV with high resolution Gatan CCD bottom camera (Orius SC200)). Photoluminescence (PL) was recorded using the Ocean Optics USB 2000 with optical fibers.

\section{Results and Discussions}

\subsection{Quantum dots of CdSe and CdS of increasing sizes}

Absorption spectra for series of quantum dots of CdSe and CdS with increasing different sizes are presented in Fig. (1a. and 1b.), respectively. The spectra for CdSe $(x=0)$ show absorption peaks that shift from 517 to $565 \mathrm{~nm}$. These shifts are due to the increasing in the size resulting from increasing growth time in solution. The spectra for CdS $(x=1)$ show also absorption peaks that shift from 389 to $415 \mathrm{~nm}$ due to the increasing sizes

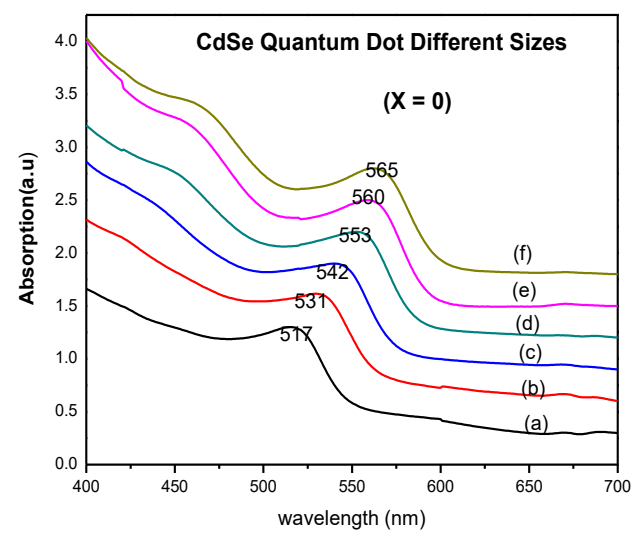

Fig. (1a). Absorption spectra for six samples of CdSe QD labeled from (a) to (f).

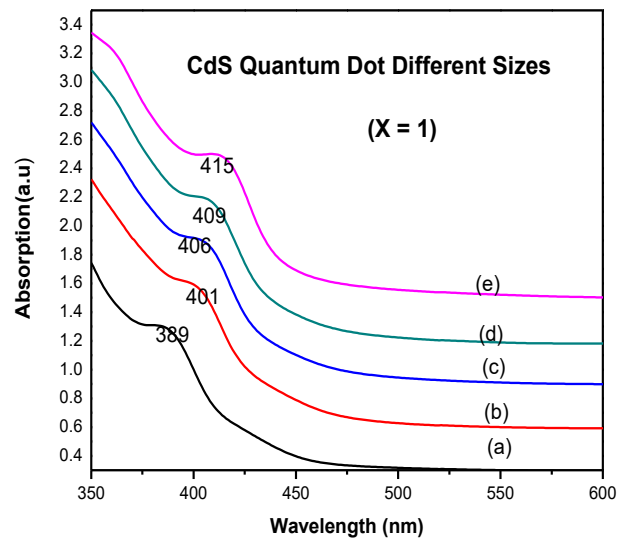

Fig. (1b). Absorption spectra for five samples of CdS QD labeled from (a) to (e).

The size of the nanoparticles was estimated from the corresponding absorption peaks by applying, the effective mass approximation (EMA) : 


$$
E_{g}(N C)=E_{g}(b u l k)+\frac{\hbar^{2} \pi^{2}}{2 m a^{2}}-\frac{1.8 e^{2}}{\varepsilon a}
$$

where $E_{g}(\mathrm{NC})$ is the lowest energy for electronic transition for nanocrystals, $E_{g}$ (bulk) is the band gap of material bulk $(=1.74 \mathrm{eV}$ for CdSe, and $=2.42 \mathrm{eV}$ for $\mathrm{CdS}), \mathrm{m}$ is the reduced mass $\left(=0.92 \times 10^{-31} \mathrm{~kg}\right.$ for CdSe and $=1.40 \times 10^{-31} \mathrm{~kg}$ for $\mathrm{CdS})$, a is the average particle radius, $\varepsilon$ is the dielectric constant $(=10.6$ for $\mathrm{CdSe}$ and $=5.7$ for $\mathrm{CdS}$ ) and e is electron charge. The calculated diameters of $\mathrm{CdSe}$ for samples $(\mathrm{a} \rightarrow \mathrm{f})$ using EMA were $(4.40,4.63,4.79,5.00,5.14$ and $5.24 \mathrm{~nm})$, respectively. In the case of CdS the diameters were $(3.02,3.20,3.26$, 3.33 and $3.42 \mathrm{~nm})$ for samples $(\mathrm{a} \rightarrow \mathrm{e})$, respectively.

The dimensions of CdSe and CdS nanoparticles were also measured using the high-resolution transmission electron-microscopy HRTEM. The graph for CdSe sample f (6 minutes growth) is shown in Fig. (2a) and for CdS sample b (5 minutes growth) is shown Fig. (2b). The estimated particle size for CdSe was $4.8 \mathrm{~nm}$ and for CdS was $3.2 \mathrm{~nm}$. The measurements estimated sizes of the NPs using EMA are in good agreement with the values measured directly by HRTEM.

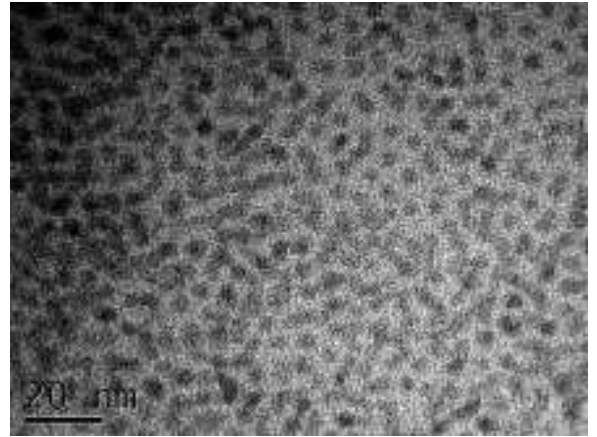

Fig. (2a). HRTEM for CdSe nano Particles (6 minutes growth)

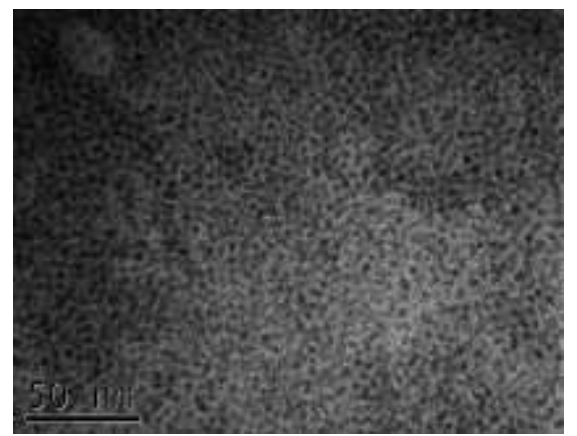

Fig. (2b). HRTEM for CdS nano Particles (5 minutes growth)

\section{Alloy $\mathrm{CdS}_{\mathrm{x}} \mathrm{Se}_{1-\mathrm{x}}$ nanocrystals}

UV-Vis absorption spectra for alloy $\mathrm{CdS}_{\mathrm{x}} \mathrm{Se}_{1-\mathrm{x}}$ nanocrystals $(x=0.33$, $0.5,0.67,0.75)$ with approximately the same growth time are shown in Fig. (3) (a) for the indicated sulphur to selenium ratio. Alloyed samples of same time growth were expected to be of the same size. The absorption of the alloyed crystal shows a single peak that blue shifts with the increase of the sulphur in molar ratio $(\mathrm{S} / \mathrm{S}+\mathrm{Se})$. The observation of single peak for the exciton of the alloy nanocrystal, indicates that the samples are true alioy. 

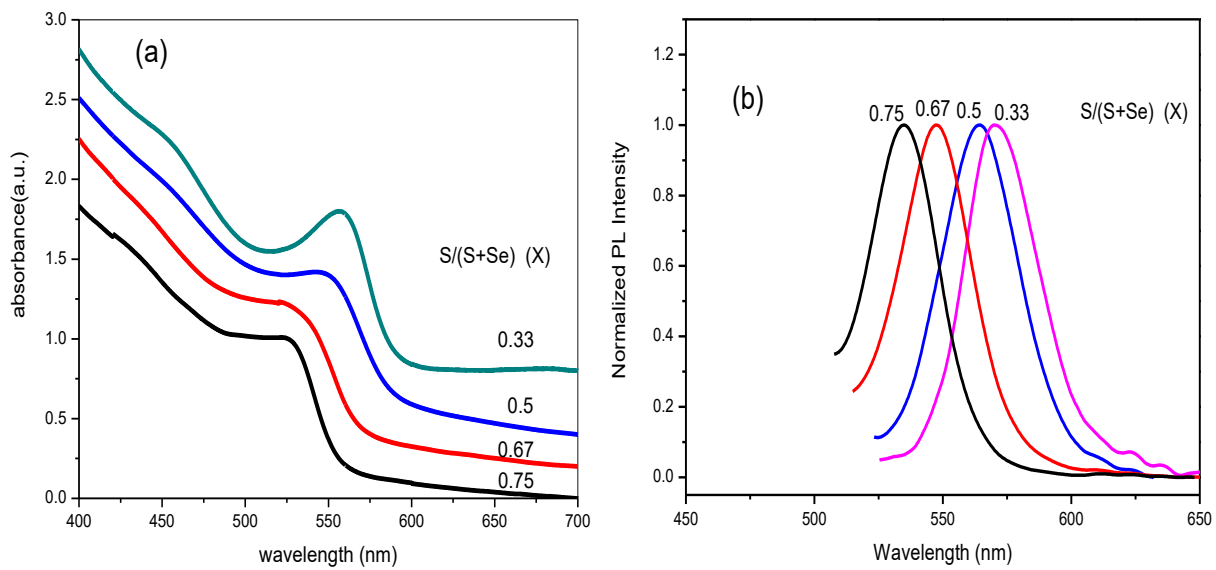

Fig. (3): UV-Vis absorption spectra (a) and PL spectra (b) of the $\mathrm{CdS}_{\mathrm{x}} \mathrm{Se}_{1-\mathrm{x}}$ nanocrystals with different ratios (a) $\mathrm{x}=0.33$, (b) $\mathrm{x}=0.50$, (c) $\mathrm{x}=0.67$ and $(\mathrm{d}) \mathrm{x}=0.75(\mathrm{~S} / \mathrm{S}+\mathrm{Se})$.

The PL emission spectra for the 4 different composition ratio $x$ samples were recorded with an excition wavelength $473.5 \mathrm{~nm}$ and are shown in Fig. 3 (b). The calculated values of Stokes shifts from the graphs varied from $6 \mathrm{~nm}$ to 16 $\mathrm{nm}$ for the four different $x$ samples.

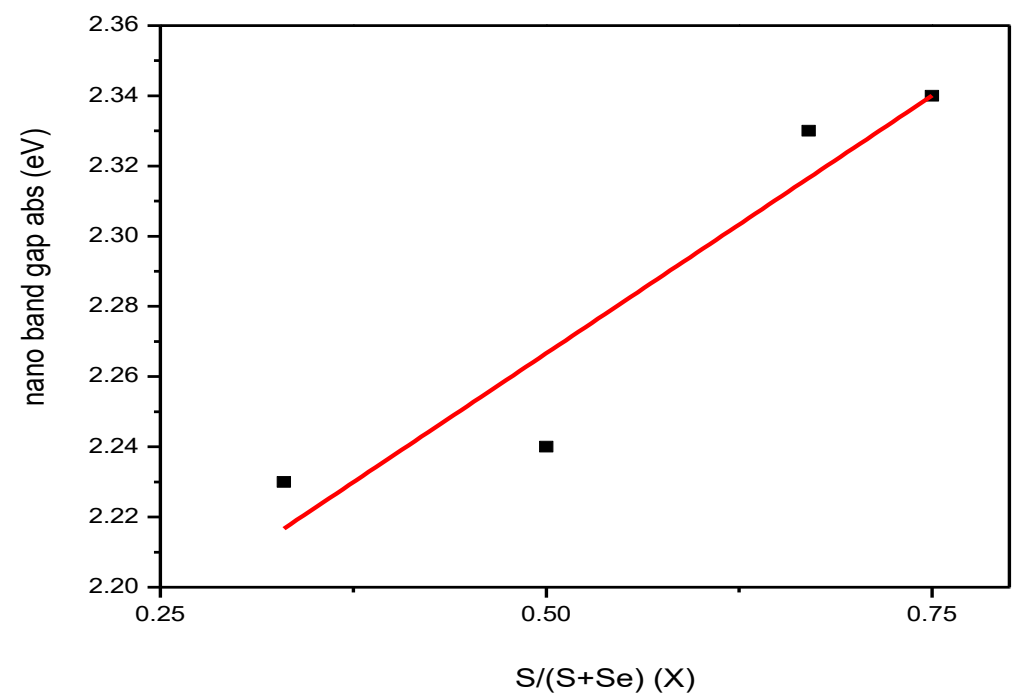

Fig. (4): shows the variation of nanocrystals bandgap energy with different $S$ concentration

The variation of the nanocrystal band gap energy as determined from the $\mathrm{UV}-\mathrm{Vis}$ spectra, with the increase in the composition ratios $(x)$ is shown in Fig. (4). It is easily seen that as the ratio of sulphur increases in the composition, the nano alloy band gap increases approximately in linear manner. 
In order to calculate the size for the alloyed nanocrystals semiconductor, we have employed Vegard's law [2], first to calculate the band gap of alloy bulk semiconductor, and then we use the (EMA) relation to get the particle size. The energy gap of the composition can be obtained using Vegard's law [xx] as follows.

$E_{g}\left(C d S_{x} S e_{1-x}\right)=x E_{g}(C d S)+(1-x) E_{g}(C d S e)-x(1-x) b$

where $x$ is the mole fraction, $\mathrm{E}_{\mathrm{g}}$ (bulk) is the band gap of bulk semiconductor (for $\mathrm{CdSe}=1.74 \mathrm{eV}$ and for $\mathrm{CdS}=2.42 \mathrm{eV}$ ) and $\mathrm{b}$ is bowing parameter $=0.3$ [9]. The corresponding reduced mass and dielectric constant for the alloyed parameters were also obtained in the same manner as above, but ignoring bowing parameter (b). The values of reduced mass and dielectric constant of CdSe where taken as $0.92 \times 10^{-31} \mathrm{~kg}$ and 10.6 , respectively. The corresponding quantity for CdS where taken as $1.40 \times 10^{-31} \mathrm{~kg}$ and 5.7, respectively.

Table (1) shows the calculated values of the energy gap, reduced masses and dielectric constants for the bulk alloy $\mathrm{CdS}_{\mathrm{x}} \mathrm{Se}_{1-\mathrm{x}}$. The calculated size values of nano alloy using UV-Vis absorption spectra for colloidal form molar ratios $(\mathrm{S} / \mathrm{S}+\mathrm{Se})$ are also shown in Table (1).

The HRTEM images of the $\mathrm{CdS}_{\mathrm{x}} \mathrm{Se}_{1-\mathrm{x}}$ nanocrystals of the molar ratios $(\mathrm{S} / \mathrm{S}+\mathrm{Se})$ values $(x)$ are shown in Fig. $5(\mathrm{a} \rightarrow \mathrm{d})$. As observed, the approximate similar size of the $\mathrm{CdS}_{\mathrm{x}} \mathrm{Se}_{1-\mathrm{x}}$ nanocrystals is $5.2 \mathrm{~nm}$.

Tables (1): include the measured sizes by HRTEM and the calculated particle size using UV-visible spectra of alloy nanoparticles for each composition parameter $(x)$. From the Table (1) the calculation sizes of nanoalloy are in good agreement with the measured one.Therefore, the use of Vegard's law is fundamental to get the alloy nanocomposite parameter.

Table (1): The band gaps, reduced masses and dielectric constants, the calculated diameters from the optical spectra and then the diameters as measured by HRTEM

\begin{tabular}{|c|c|c|c|c|c|}
\hline $\mathrm{x}$ & $\begin{array}{c}\mathrm{E}_{\mathrm{g}}(\mathrm{bulk}) \\
(\mathrm{eV})\end{array}$ & $\begin{array}{c}\text { Reduced mass } \\
(\mathrm{kg}) \mathrm{x} 10^{-31}\end{array}$ & $\begin{array}{c}\text { Dielectric } \\
\text { constant }\end{array}$ & $\begin{array}{c}\text { Diameter (UV) } \\
(\mathrm{nm}) \text { EMA 0.01 } \pm\end{array}$ & $\begin{array}{c}\text { TEM } \\
(\mathrm{nm})\end{array}$ \\
\hline 0.33 & 1.89 & 1.08 & 8.98 & 5.28 & $5.33 \pm 0.54$ \\
\hline 0.50 & 2.00 & 1.16 & 8.15 & 5.82 & $5.16 \pm 0.72$ \\
\hline 0.67 & 2.12 & 1.24 & 7.31 & 5.78 & $5.31 \pm 0.54$ \\
\hline 0.75 & 2.19 & 1.28 & 6.92 & 6.34 & $4.91 \pm 0.45$ \\
\hline
\end{tabular}




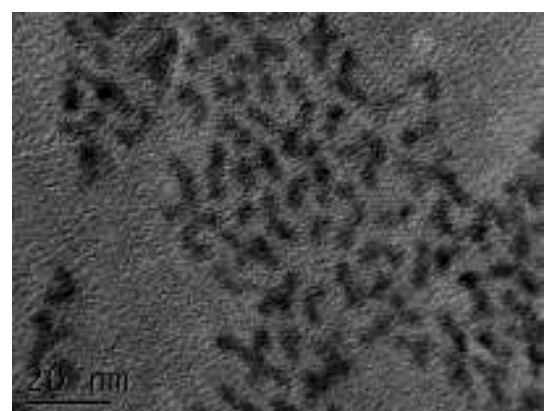

$x=0.33$

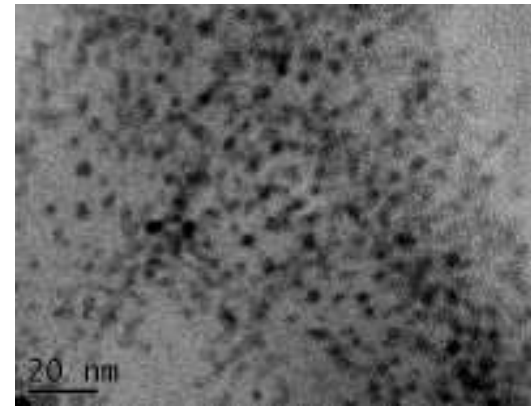

$x=0.67$

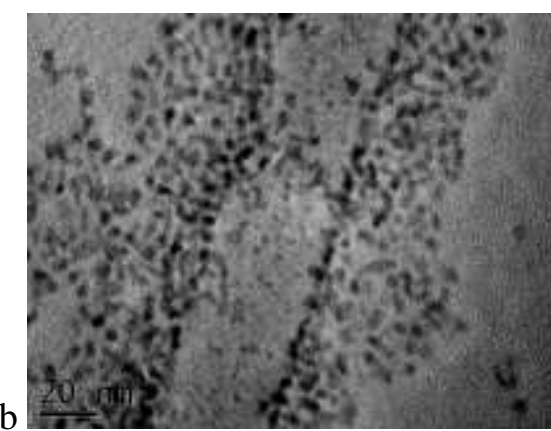

$x=0.50$

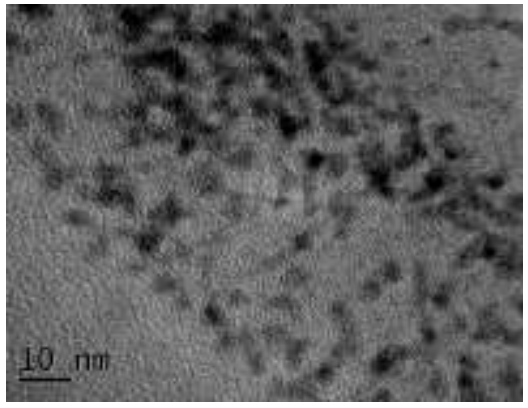

$x=0.75$

Fig. (5): HRTEM images of nano alloy CdSSe with different ratio $\mathrm{S} /(\mathrm{S}+\mathrm{Se})=($ (a) 0.33 , (b) 0.5 , (c) 0.67 and (d) 0.75 ) approximation of size $5.2 \mathrm{~nm}$.

\section{Conclusions}

Alloyed semiconductor nanostructure of approximately the same size but varied composition of $\mathrm{CdS}_{\mathrm{x}} \mathrm{Se}_{1-\mathrm{x}}(\mathrm{x}=0 \rightarrow 1)$ were synthesized using chemical deposition method .The alloyed nanostructure were characterized by UV-Visble in colloidal form and HRTEM. The use of Vegard's law to determine the nano alloy parameter is fundamental to get the nano alloy sizes. That is in close agreement with the measured values as measured by HRTEM.

\section{Acknowledgment}

The Support of the Science and Technology Development Fund (STDF) Grant ID 377 is greatly appreciated. 


\section{eferences}

1. N. P. Gurusinghe, N.N. Hewa-Kasakarage, and M. Zamko, J. Phys. Chem. C, 112, 12795 (2008).

2. M. D. Garrett, A.D. Dukes III, J. R. McBride, N. J. Smith, S. J. Pennycook, and S. J. Rosenthal, J. Phys. Chem. C, 112, 12736 ( 2008).

3. X. Chena, J. L. Hutchisona, P. J. Dobsonb, G. Wakefield. Materials Science and Engineering B, 166, 14 (2010).

4. L.F. Xi, W. X.W. Tan, K.S. Chua, C. Boothroyd, Y.M. Lam, Thin Solid Films., 517, 2430 (2009).

5. L. Z. Ve'gard, Phys, 5, 17 (1921).

6. L. E. Brus, J. Phys Chem., 90, 2555 (1986).

7. D. V. Talapin, A. L. Rogach, A. Kornowski, Nanoletters, 1, 207 (2001).

8. D. Tonti, F. Van Mourik, M. Chergui, Nano Lett., 4, 2483 (2004).

9. L. A Swafford, L. A. Weigand, M. J. Bowers, J. R. McBride, J. L. Rapaport, T. L. Watt, S. K. Dixit, L. C. Feldman, S. J. Rosenthal, J. Am. Chem. Soc., 128, 12299 (2006). 